\title{
Increased Number of Whistles of Bottlenose Dolphins, Tursiops truncatus, Arising from Interaction with People
}

\author{
Junko AKIYAMA ${ }^{1)}$ and Mitsuaki OHTA ${ }^{1)}$ \\ ${ }^{1)}$ Laboratory of Animal and Human Interaction, Azabu University School of Veterinary Medicine, 1-17-71 Fuchinobe, Sagamihara, \\ Kanagawa 229-8501, Japan
}

(Received 9 August 2006/Accepted 1 November 2006)

\begin{abstract}
The acoustic mode is the most reasonable means for social animals such as dolphins to maintain contact in the underwater habitat, and has been developed since they moved to the sea. This study investigates variations in dolphin vocalizations under the following conditions in a captive environment: 1) before feeding (Pre-feeding), 2) during feeding (Feeding), 3) during free time without the presence of people (Free), 4) during interaction with people located upon a float (Float), 5) during interaction with people in the water (Water). During the experiments, a total of 2642 whistles were extracted from sonogram data using a spectrogram. About $44 \%$ of the total whistles were observed during Pre-feeding (1171/2642), and the number recorded during Free, when people were absent, was the smallest. The acoustic contours of dolphin whistles differed in different situations: convex, wave, and trill whistles were made repeatedly during Pre-feeding, thereby being more common at this time than at other times. The situation of Feeding saw an increased number of Upsweeps, which might be related to the use of echolocation. The lower frequencies were recorded during Pre-feeding, reflecting the emotion related to the dolphin's hunger. The results of this study indicate that dolphins increase their vocalization during interaction with people, suggesting that interactions with dolphins provide an effective treatment for human health problems, which is discussed with a reference article in this study. Vocal data obtained during contact with humans might serve as an important index for the dolphinassisted therapy.

KEY WORDS: bottlenose dolphin, captive environment, dolphin-human interaction, vocalization.
\end{abstract}

Bottlenose dolphins, Tursiops truncatus, are kept in many aquaria and marine facilities throughout the world. They have a wide distribution and inhabit almost every ocean. The brain of the bottlenose dolphin is heavier than that of the human brain, and the bottlenose dolphin's brain index \{brain weight/(body size $)^{2 / 3}$, which is the ratio of brain size to body size, is the second-largest (0.64) of all mammals after humans (0.89); this value is more than twice that of chimpanzees (0.30) [16]. Dolphins have developed a complex social structure [8] and make use of tools [13]. Several experiments that target cognitive mechanisms have demonstrated dolphins' capabilities in terms of learning, memory, and communicative language [11].

Most marine-derived dolphins form communities, called pods, and are considered to mutually communicate. They often use characteristic vocalizations for communication rather than touch and breaching [24]. The dolphin has developed a means of sound communication that can carry a wide range and send myriad messages rapidly through water. Dolphins gather information through hearing. Their sophisticated communication system improves their efficiency in searching for food, reproduction, and protection; thereby enhancing their adaptation to the environment [6].

Dolphins produce sounds in the range $10 \mathrm{~Hz}$ to $160 \mathrm{kHz}$ [10], which are categorized as either pulse or non-pulse sound. Clicks (pulses) commonly extend into the ultrasound region for the purpose of echolocation, and last for only a few tens or hundreds of microseconds. The other pulses, burst pulse sounds, seem to be related to the dolphin's emotional state $[3,7]$. Whistles are non-pulse, have a narrow frequency band below $20 \mathrm{kHz}$, and are of long duration. Whistles appear to serve an important role in communication among dolphins [19]. Individual dolphins identify themselves using a signature whistle: dolphins use the whistle to identify and call their calves and other group members [20].

Wild dolphins adapt to their natural environment, changing behavior and sense appropriately. Captive dolphins also adapt to their respective environments and show simpler behavior and fewer calls than wild dolphins. In contrast, long-term captive seals show poor variation in vocalization [21].

Dolphins change behavioral patterns according to their captive environment. The main difference between natural and captive environments might well be the presence of humans; consequently, any association with humans would be expected to result in a change in the dolphin's behavior. Following this theme, the present study investigates variations in dolphins' whistles under different conditions within a captive environment.

\section{MATERIALS AND METHODS}

Animals: The three captive bottlenose dolphins, Tursiops truncatus, were used in this study included one male and two females of 5-8 years of age. They were housed together in a sea pen $(20 \times 60 \mathrm{~m}, 6-10 \mathrm{~m}$ depth $)$ at a facility in Muroto, Kochi, Japan. Two of the dolphins had been kept since 6 August 2003 and the other female since 28 February 2004. The dolphins are fed and trained four times daily, 
including two sessions where they are fed by guests. Their health condition is regularly monitored by two veterinarians with a good knowledge of dolphins. A program through which disabled persons could come in contact with the dolphins was conducted during the summer (June-November) of 2004.

Data collection and analysis: Whistles of the studied dolphins were recorded together using a Whale Phone (Oki Electric Industry Inc., Shizuoka, Japan) with a hydrophone, a digital audio tape recorder (TCD-D10, Sony Corp., Tokyo, Japan), and a portable mini-disk recorder (MZ-N10, Sony Corp.). Microphones were set $3 \mathrm{~m}$ under the platform in the sea pen, and the system had a frequency response of $20 \mathrm{~Hz}$ to $20 \mathrm{kHz}$.

The whistles of three dolphins, but not individually, were collected for 10-15 min during various daily situations: 1) immediately before feeding (Pre-feeding), 2) during feeding (Feeding), 3) during free time without the presence of people (Free), 4) during interaction with people upon a float (Float), and 5) during interaction with people in the water (Water).

Data recorded on six different days during the 5 months of observations were converted into sonograms using a free software package (Spectrogram; Richard Horne), and shown as the numbers per $10 \mathrm{~min}$.

Whistle contours were classified as one of seven types (Fig. 1): Constant, Upsweep, Downsweep, Concave, Convex, Wave, and Trill, using a modified version of BazuaDuran and Au's six-part classification [5]. The different types of whistle contours are defined as follows:

I Constant: A contour in which the frequency changes by less than $1000 \mathrm{~Hz}$.

II. Upsweep: A contour in which the frequency is mainly ascending.

III. Downsweep: A contour in which the frequency is mainly descending.

IV. Convex: A contour with at least one inflection point at which the frequency is first mainly ascending and then mainly descending.

V. Concave: A contour with at least one inflection point at which the frequency is first mainly descending and then mainly ascending.

VI. Wave: A contour with two inflection points at which the frequency is first mainly ascending, then mainly descending, or vice versa (termed 'Sine' in BazuaDuran and $\mathrm{Au}[5])$.

VII. Trill (the original whistle contour in this study): A contour with more than three inflection points in which the frequency is repeated for the entire duration of the whistle.

The frequency resolution was set to $86.1 \mathrm{~Hz}$ and the time resolution to $5 \mathrm{msec}$. Six parameters were extracted from the sonograms of each whistle following the method of Wang et al. [22] and Bazua-Duran and Au [5]: 1) beginning frequency, 2) end frequency, 3) maximum frequency, 4) minimum frequency, 5) frequency span, and 6) duration (Fig. 2). The frequency span is the difference between the maximum and minimum frequency, while the duration is the difference between the beginning and end times of the whistle.

The differences in the numbers of whistles between Free and the other situations, and the comparison of the five main situations of daily life (Free, Pre-feeding, Feeding, Float and Water) with the six parameters of whistle components (Begin, End, Minimum, Span, and Duration) were tested using one-way ANOVA as well as the multiple-comparison post hoc tests.

\section{RESULTS}

A total of 2642 whistles were extracted from the records. The frequency span was $6.54 \pm 2.56 \mathrm{kHz}$ (mean $\pm \mathrm{SD}$, $\mathrm{N}=2642$ ): $73 \%$ of the whistles were in the range $5-10 \mathrm{kHz}$ and $4.2 \%$ were $<1 \mathrm{kHz}$. The whistle durations were $1.25 \pm$ $0.91 \mathrm{sec}$ : $41 \%$ were less than $1 \mathrm{sec}$ and $10 \%$ were longer than $5 \mathrm{sec}$.

About $44 \%$ of the total whistles were observed during Pre-feeding, whose number (mean \pm SD, $195.2 \pm 57.5$ ) was significantly different from that during Free $(42.7 \pm 4.9$, $P<0.01$; Dunnett's multiple-comparison test) (Fig. 3, Table 1). The numbers of whistles also increased during Feeding, Float and Water, although they were not statistically significant, compared to the number recorded during Free, which was without people. The lowest number of Float on the first observation might be due to the dolphin's landing on the float, in which the sound was not recorded (Fig. 3).

The recorded numbers of each whistle type varied among the five situations (Table 1). The numbers of whistles during Free were lowest for all types of whistle contours. Convex, wave, and trill whistles were commonly repeated during Pre-feeding, and thus appeared much more in this situation than in others. The numbers of upsweep, convex, and trill whistles increased during Feeding, as did the number of trill whistles during Float and Water. Little difference was apparent in the numbers of constant, downsweep, and concave whistle contours among different situations.

Table 2 shows descriptive statistics (mean, standard deviation, and highest and lowest values) of the six parameters of whistle components for the five main situations of the daily life of the dolphins. The beginning frequency was higher than the end frequency during Pre-feeding, but all the others show larger values in the end frequency. The frequency span was the widest during Pre-feeding, and the whistle duration was longest during Water $(1.83 \pm 1.49 \mathrm{sec})$.

\section{DISCUSSION}

The captive bottlenose dolphins analyzed in this study showed changes in the number of whistle contours in several of the situations of daily life. Delphinids produce different sounds related to their behavioral context according to changes in feeding, sexual play, aging, etc [12, 14, 23]. The whistles of the studied dolphins during Free, without interaction with people, occurred at the lowest levels for all 


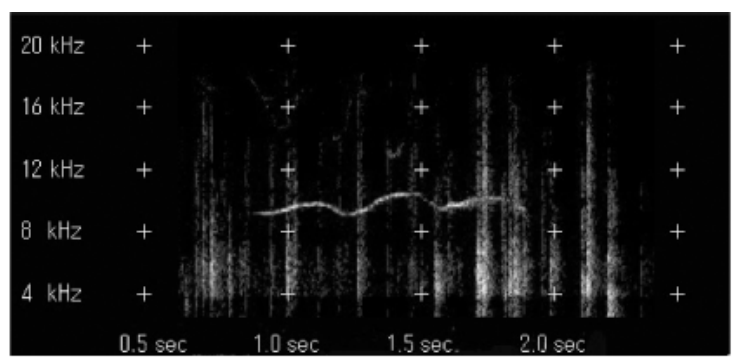

\section{I . Constant}

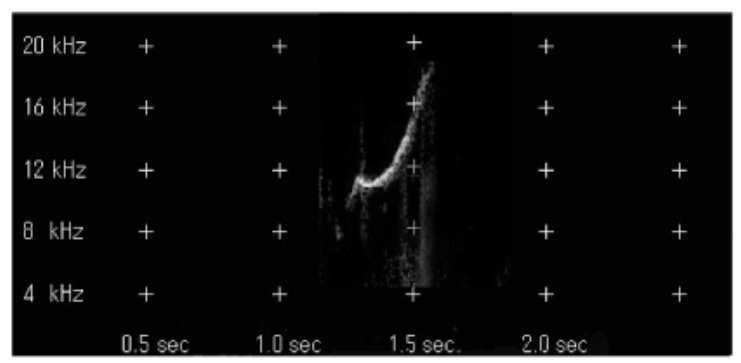

II . Upsweep

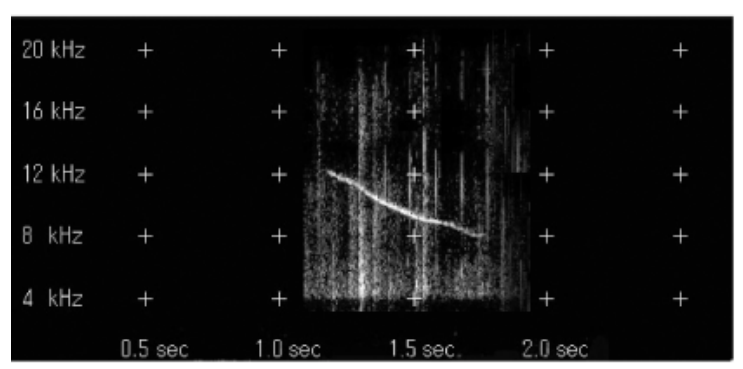

III. Downsweep

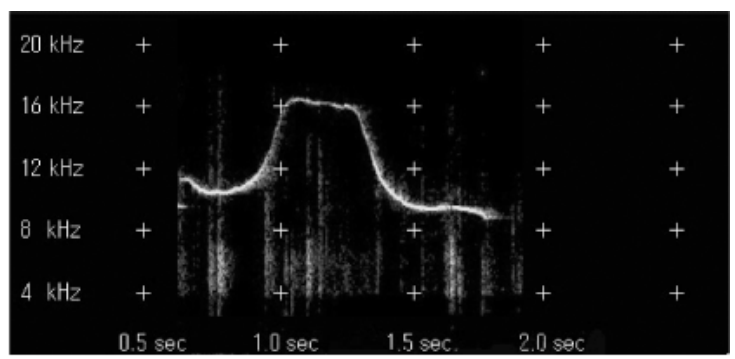

IV. Convex

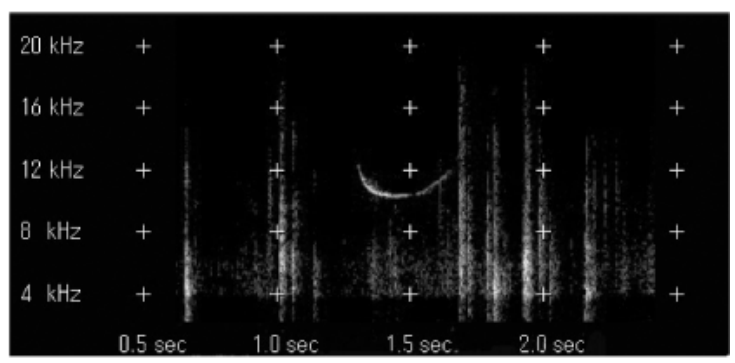

V. Concave

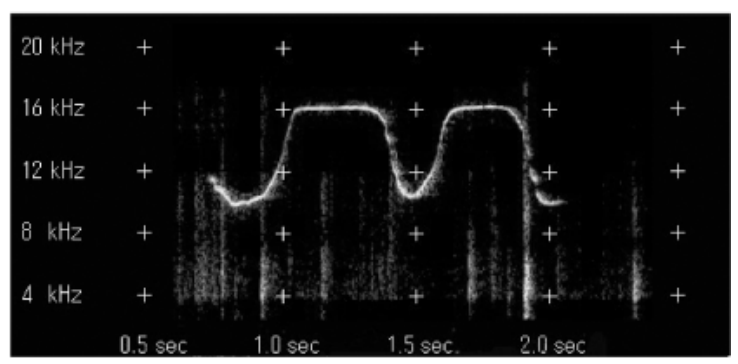

VI. Wave

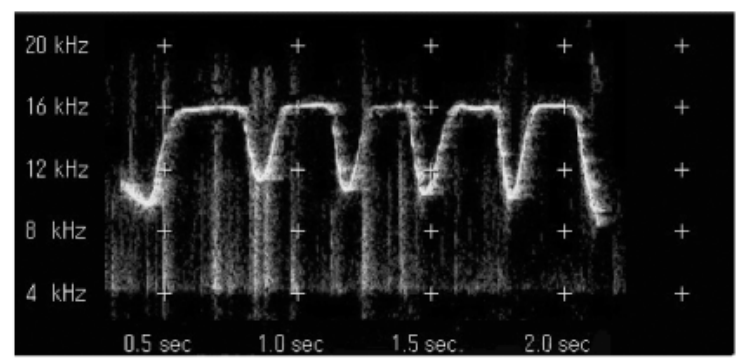

\section{Trill}

Fig. 1. The seven types of whistle contours (I-VII) converted into sonograms.

contour types, whereas whistles during others situations occurred in greater numbers. The large numbers of whistles in Pre-feeding were due to repeated Convex, Wave, and Trill whistles.

The pod sizes of several dolphin species increase during feeding events [15]. Dusky porpoises produce greater numbers of characteristic calls or a greater number of total calls in order to recruit individuals to feeding events [25]. The whistles of bottlenose dolphins are also more numerous among feeding groups than non-feeding groups [1]. The large increase in the number of whistles during Pre-feeding recorded in our study might reflect the timing of feeding events, suggesting a demand for food. In dogs, acoustic communication via barking has multiple meanings in defense, play, display, attention, and caution. Excitement caused by the frequency of barking has been found to corre- 


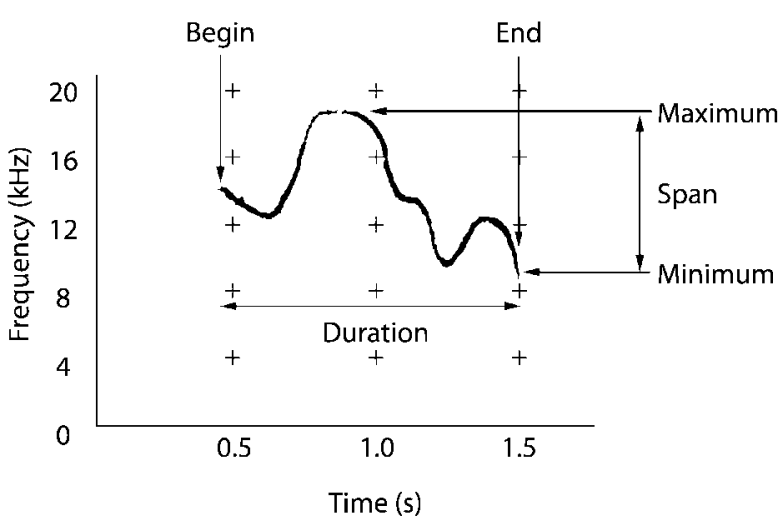

Fig. 2. The six parameters of beginning frequency, end frequency, maximum frequency, minimum frequency, frequency span, and duration measured from each whistle contour.

late with the degree of tension [9]. The sound is said to be sent correctly to the target of the call by repeating a limited repertory of signals to make it easily understood. In our case, reiteration of the whistle during Pre-feeding appears to arise during a state of tension when seeking food.

The situations of Feeding, Float, and Water also led to increases in the numbers of whistles, except the first of ser- ration during Float (Fig. 3). The only difference between Free and other situations including Pre-feeding was interaction with people, including dolphin trainers. Antonioli and Reveley [2] documented that animal-facilitated therapy with dolphins is an effective treatment for mild to moderate depression, and suggested that healing properties are derived from the emotions raised by interaction with dolphins and the sounds of the dolphins, including the echolocation system. In the present study, the situations that involved human-dolphin interaction were characterized by increased sounds, especially Trill whistle contour.

The minimum frequency during Pre-feeding showed the lowest level of all situations, as with the end frequency. In humans, a definite relation exists between the acoustic characteristics of vocalization and emotion [17]. Characteristically, the mean of the fundamental frequency is high for the emotions of happiness and amazement and is low for sadness [18]. The low levels of whistle frequency recorded during Pre-feeding might reflect the emotion of sadness related to the dolphins' hunger.

The whistle duration of bottlenose dolphins in nature is less than $1 \mathrm{sec}[22]$, whereas the mean duration in the present study is longer than $1 \mathrm{sec}$ in all situations, even up to $8 \mathrm{sec}$ for Water. Bazúa-Durán [4] reported for spinner dolphins that their whistle duration depended on the group size

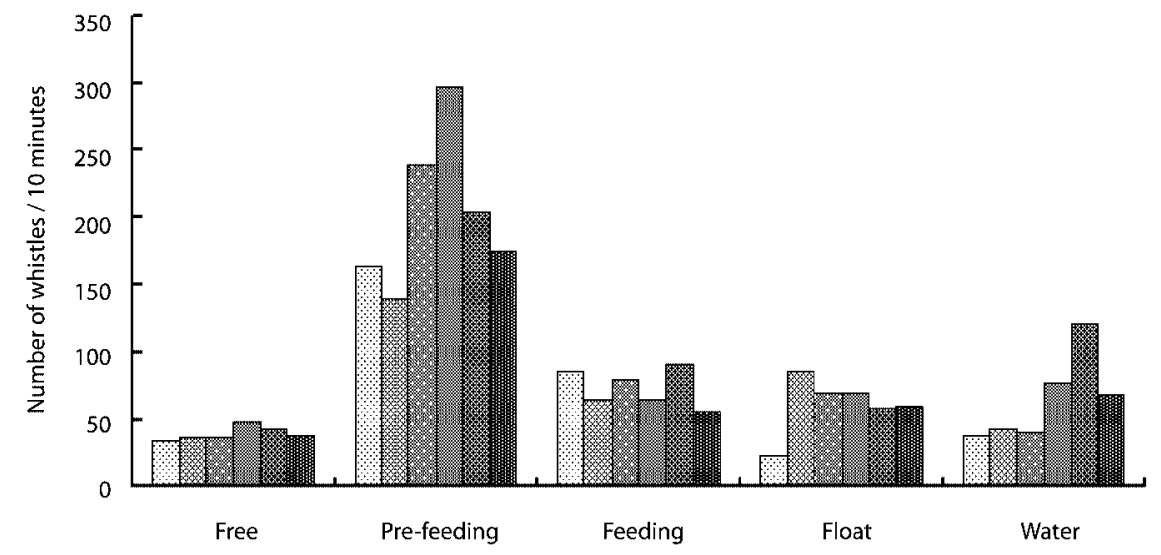

Fig. 3. The numbers of whistles per $10 \mathrm{~min}$ on six different days during the 5 months of observations. The columns of the five situations are placed according to the order of experiments.

Table 1. Comparison of the total numbers of whistle contours in five situations

\begin{tabular}{lcccrrr}
\hline $\begin{array}{l}\text { Whistle } \\
\text { categories }\end{array}$ & Free & $\begin{array}{c}\text { Pre- } \\
\text { feeding }\end{array}$ & Feeding & Float & Water & Total \\
\hline Constant & 32 & 58 & 38 & 46 & 57 & 231 \\
Upsweep & 32 & 44 & 100 & 63 & 43 & 281 \\
Downsweep & 11 & 23 & 17 & 15 & 15 & 81 \\
Convex & 63 & 465 & 131 & 75 & 78 & 812 \\
Concave & 3 & 9 & 12 & 6 & 2 & 32 \\
Wave & 38 & 205 & 40 & 48 & 33 & 363 \\
Trill & 77 & 368 & 126 & 134 & 136 & 842 \\
\hline Total & 256 & 1171 & 464 & 387 & 364 & 2642 \\
\hline
\end{tabular}


Table 2. Comparison of the descriptive statistics (mean, standard deviation, highest and lowest values) of six parameters of the whistles component in five situations of daily life. Value followed by different alphabet within each column are significant at $P=0.01$ (Tukey's multiple-comparison test).

\begin{tabular}{|c|c|c|c|c|c|c|c|c|}
\hline & \multirow{2}{*}{$\begin{array}{l}\text { Discriptive } \\
\text { Statistics }\end{array}$} & \multicolumn{5}{|c|}{ Frequency $(\mathrm{kHz})$} & \multirow{2}{*}{$\frac{\text { Time }(\mathrm{sec})}{\text { Duration }}$} & \multirow[b]{2}{*}{$N$} \\
\hline & & Begin & End & Minimum & Maximum & Span & & \\
\hline \multirow[t]{4}{*}{ Free } & Mean & $12.13^{\mathrm{a}}$ & $12.51^{\mathrm{egh}}$ & $10.85^{\mathrm{i}}$ & $16.41^{\mathrm{mn}}$ & $5.56^{\mathrm{q}}$ & $1.40^{\mathrm{u}}$ & \multirow[t]{4}{*}{256} \\
\hline & S.D. & 2.77 & 3.66 & 2.38 & 3.62 & 2.82 & 1.21 & \\
\hline & Highest & 20.03 & 20.11 & 18.39 & 21.06 & 11.71 & 6.90 & \\
\hline & Lowest & 1.15 & 4.18 & 4.18 & 4.44 & 0 & 0.05 & \\
\hline \multirow[t]{4}{*}{ Pre-feeding } & Mean & $11.57^{\mathrm{b}}$ & $9.67^{\mathrm{f}}$ & $9.10^{\mathrm{j}}$ & $16.26^{\mathrm{mn}}$ & $7.18^{\mathrm{r}}$ & $1.13^{\mathrm{v}}$ & \multirow[t]{4}{*}{1171} \\
\hline & S.D. & 1.96 & 2.22 & 1.37 & 2.66 & 2.57 & 0.48 & \\
\hline & Highest & 17.69 & 19.60 & 16.24 & 20.28 & 18.13 & 3.82 & \\
\hline & Lowest & 1.22 & 0.71 & 1.68 & 3.23 & 0 & 0.02 & \\
\hline \multirow[t]{4}{*}{ Feeding } & Mean & $11.35^{\mathrm{b}}$ & $11.96^{\text {eh }}$ & $9.86^{\mathrm{k}}$ & $15.84^{\mathrm{m}}$ & $5.98^{\mathrm{q}}$ & $1.07^{\mathrm{v}}$ & \multirow[t]{4}{*}{464} \\
\hline & S.D. & 2.69 & 4.00 & 2.49 & 3.42 & 2.84 & 0.88 & \\
\hline & Highest & 19.60 & 20.97 & 18.30 & 21.32 & 14.47 & 9.26 & \\
\hline & Lowest & 1.15 & 1.02 & 1.15 & 4.18 & 0 & 0.02 & \\
\hline \multirow[t]{4}{*}{ Float } & Mean & $12.17^{\mathrm{a}}$ & $12.89^{\mathrm{g}}$ & $10.93^{\mathrm{i}}$ & $16.69^{\mathrm{n}}$ & $5.75^{\mathrm{q}}$ & $1.48^{\mathrm{u}}$ & \multirow[t]{4}{*}{387} \\
\hline & S.D. & 2.49 & 3.73 & 2.32 & 3.26 & 2.84 & 1.27 & \\
\hline & Highest & 21.06 & 21.15 & 18.99 & 21.49 & 13.61 & 8.57 & \\
\hline & Lowest & 1.24 & 3.57 & 3.57 & 5.73 & 0 & 0.06 & \\
\hline \multirow[t]{4}{*}{ Water } & Mean & $11.37^{\mathrm{b}}$ & $11.83^{\mathrm{h}}$ & $9.90^{\mathrm{k}}$ & $15.86^{\mathrm{m}}$ & $5.97^{\mathrm{q}}$ & $1.83^{w}$ & \multirow[t]{4}{*}{364} \\
\hline & S.D. & 2.57 & 3.06 & 2.06 & 3.44 & 2.73 & 1.49 & \\
\hline & High & 19.25 & 20.03 & 16.24 & 20.72 & 17.36 & 8.15 & \\
\hline & Low & 5.38 & 5.64 & 1.63 & 5.64 & 0 & 0.07 & \\
\hline
\end{tabular}

and different general behavioral states: social, travel, or rest. The Water situation is different from other states in that people are close to the dolphins. The behavior of the dolphins during Water implies that the dolphins attempt to communicate with people who are in the water with them.

Repeatedly vocalizations by dolphins during Pre-feeding resemble types of Convex whistles such as Wave and Trill contours that change shape at the end of the inflection, suggesting the emotions of hunger or demand. The characteristic contour during Feeding is the upsweep. The increased frequency of the Upsweep contour might be related to echolocation, as cetaceans produce sounds during foraging because they use echolocation clicks to detect and pursue prey [3].

During the situation of Free time, when the aquarium was free of people, the dolphins fell silent. Incidentally, the whistles became more numerous and longer when a dolphin interacted with a new person than those when interacting with a familiar person. A greater variety of whistles were produced when a greater number of people were in the water. Further research is required to explore the possibility that dolphins seek to actively communicate with humans as well as the differences in individual sound and in gender.

Dolphins increase their vocalization in situations where they interact with people, suggesting an effective treatment for human health via interactions with dolphins. Vocal data obtained during contact with humans might serve as an important index that can be used to improve dolphin-human interactions, especially for the dolphin-assisted therapy.

ACKNOWLEDGEMENTS. This study was supported in part by the Grant-in-Aids for Scientific Research from the
Commemorative Foundation for the International Garden and Greenery Exposition, Osaka, and from the Ministry of Education, Culture, Sports, Science and Technology in Japan (18858116).

\section{REFERENCES}

1. Acevedo-Gutiérrez, A. and Stienessen, S. C. 2004. Bottlenose dolphins increase number of whistles when feeding. Aqua. Mamm. 30: 357-362.

2. Antonioli, C. and Reveley, M. A. 2005. Randomised controlled trial of animal facilitated therapy with dolphins in the treatment of depression. Br. Med. J. 331: 1231.

3. Au, W. W. L. 1993. The Sonar of Dolphins. Springer-Verlag, New York.

4. Bazúa-Durán, C. 2001. The whistles of Hawaiian Spinner Dolphins, Stenella longirostoris, description and geographic variations. Ph.D. thesis, University of Hawaii.

5. Bazúa-Durán, C. and Au, W. W. L. 2002. The whistles of Hawai ian spinner dolphins. J. Acoust. Soc. Am. 112: 30643972.

6. Caldwell, M. C. and Caldwell, D. K. 1965. Individual whistle contours in bottlenose dolphins, Tursiops truncatus. Nature (Lond.) 207: 434-435.

7. Caldwell, M. C. and Caldwell, D. K. 1967. Intraspecific transfer of information via the pulsed sound in captive odontocete cetaceans. pp. 879-936. In: Animal Sonar Systems: Biology and Bionics, Laboratoire de Physiologie Acoustique, Jouy-deJosas, France.

8. Connor, R. C., Heithaus, M. R. and Barre, L. M. 2001. Complex social structure, alliance stability and mating access in a bottlenose dolphin 'super-alliance'. Proc. Biol. Sci. 268: 263267.

9. Coppinger, R. P. 1991. Why do dogs bark? pp. 119-129. In: Smithsonian Magazine. 
10. Evans, W. E. 1967. Vocalizations among marine mammals. pp. 159-186. In: Marine Bio-Acoustics (Tavolga, W. N. eds.), Pergamon Press, New York.

11. Herman, L. M. 1986. Cognition and language competencies of bottlenosed dolphins. pp. 221-251. In: Dolphin Cognition and Behavior: A Comparative Approach. (Schusterman, R. J., Thomas, J. and Wood, F. G.. eds.), Lawrence Erlbaum Associates, Hilladal.

12. Janik, V. M. 2000. Food-related bray calls in wild bottlenose dolphins, Tursiops truncatus. Proc. Biol. Sci. 267: 923-927.

13. Krützen, M., Mann, J., Heithaus, M. R., Connor, R. C., Bejder, L. and Sherwin, W. B. 2005. Cultural transmission of tool use in bottlenose dolphins. Proc. Natl. Acad. Sci. 25: 8939-8943.

14. McCowan, B. 1995. Maternal aggressive contact vocalizations in captive bottlenose dolphins, Tursiops truncatus: Wide-band, low-frequency signals during mother/aunt-infant interactions. Zoo Biol. 14: 293-309.

15. Norris, K. S. and Dohl, T. P. 1980. Behavior of the Hawaiian spinner dolphin, Stenella longirostris. Fish. Bull. 77: 821-849.

16. Russel, I. S. 1979. Brain size and intelligence: A comparative perspective. pp. 126-153. In: Brain Behavior and Evolution (Oakley, D. A. and Plotkin, H. C. eds.) Methuen, London.

17. Scherer, K. R. 1986. Vocal affect expression: A review and a model for future research. Psychol. Bull. 99: 143-165.

18. Scherer, K. R., Banse, R., Wallbott, H. G. and Goldbeck, T.
1991. Vocal cues in emotion encoding and decoding. Motiv. Emot. 15: 123-148.

19. Sjare, B. L. and Smith, T. G. 1986. The vocal repertoire of white whales, Delphinapterus leucas, summering in Cunningham Inlet, Northwest Territories. Can. J. Zool. 64: 407-415.

20. Smolker, R. A., Mann, J. and Smuts, B. B. 1993. Use of signature whistles during separations and reunions by wild bottlenose dolphin mothers and infants. Behav. Ecol. Sociobiol. 33: 393-402.

21. Thomas, J. A. and Kuechle, V. B. 1982. Melt pools as natural experimental arenas for acoustical studies. Antarc. J. 16: 187 188.

22. Wang, D. W., Würsig, B. and Evans, W. E. 1995. Whistles of bottlenose dolphins: comparisons among populations. Aqua. Mamm. 21: 65-77.

23. Weilgart, L. and Whitehead, H. 1990. Vocalizations of the North Atlantic pilot whale, Globicephala melas, as related to behavioral contexts. Behav. Ecol. Sociobiol. 26: 399-402.

24. Würsig, B. and Würsig, M. 1979. Behavior and ecology of the bottlenose dolphin, Tursiops truncatus, in the South Atlantic. Fish. Bull. 77: 399-412.

25. Würsig, B. and Würsig, M. 1980. Behavior and ecology of dusky porpoises, Lagenorhynchus obscurus, in the South Atlantic. Fish. Bull. 77: 871-890. 